\title{
O NIILISMO PÓS-GUERRA EM H.P. LOVECRAFT: UMA ANÁLISE HISTÓRICO-FILOSÓFICA DE DAGON (1919)
}

\author{
THE POSTWAR NIHILISM IN H. P. LOVECRAFT: A HISTORICAL-PHILOSOPHICAL \\ ANALYSIS OF DAGON (1919)
}

\begin{abstract}
Alexandre Bartilotti Machado e Savio Queiroz Lima²
1 Universidade do Estado da Bahia- UNEB- Campus I. E-mail: alexandrebmachado@yahoo.com, ORCID: https://orcid.org/0000-0002-9561-8721

2 Universidade Salgado de Oliveira, Programa de Pós-Graduação em História da Universidade Salgado Niterói,/RJ, Brasil, E-mail: savio roz@yahoo.com.br, ORCID: https://orcid.org/0000-0003-1167-5639
\end{abstract}

\section{ARTICLE INFO \\ Article history: \\ Received 2020-08-31 \\ Accepted 2020-12-12}

Available online 2020-12-12
Palavras-chave: Lovecraft; Primeira Guerra Mundial; Niilismo; Nietzsche; Chartier.

Keywords: Lovecraft; World War One; Nihilism; Nietzsche; Chartier.

RESUMO. Esta reflexão pretende pontuar as características em dinâmica que norteiam o conto Dagon, de Howard Phillips Lovecraft, e seu pertencimento histórico. Conto curto, Dagon fornece inúmeros elementos pertinentes para entender modos de pensar a realidade histórica no começo do século XX e suas heranças existenciais do final do século XIX. Trata de uma abordagem sensível sobre os elementos psicológicos, filosóficos e alegóricos que constituem a narrativa ficcional gótica de 1919. Como base teórica, os conceitos de Representação e Niilismo, frutos dos diálogos com Roger Chartier e Friedrich Nietzsche, respectivamente, nos são instrumentos possíveis de análise da fonte ficcional na interpretação da realidade histórica. Através dessa análise histórico-filosófica, esmiúça-se o conto Dagon para entender os aspectos construtivos de seu cenário verossimilhante e reconhecível de tempos bélicos e tal entrega interpessoal desesperante.

ABSTRACT. Through this paper, it is our intent to point out the characteristics surrounding the short story Dagon, from Howard Phillips Lovecraft, and its historical belonging. As a short story, Dagon provides countless useful elements to our understanding of ways of thinking historical reality in the beginning of the twentieth century and its existencial inheritances by the end of the nineteenth century. It approaches psychological, philosophical and allegorical issues that built the gothic narrative from 1919. As theoretical ground, the concepts of Representation and Nihilism, born from Roger Chartier and Friedrich Nietzsche, respectively, it gives us ways to analyze the fictional source while interpreting historical reality. Through this historical-philosophical analysis, we look upon Dagon to understand its constructives aspectos of its likelihood landscape and recognizable from war times and such interpersonal and desperate narrative.

\section{Introdução}

As cearas ficcionais sintomatizam a realidade que muitas vezes mimetiza 0 esteio ficcional das dinâmicas sociais, principalmente no que diz respeito às identidades sociais. Em nossa contemporaneidade, marcada pela ascensão de teorias pósmodernas na esfera intelectual e por uma economia capitalista neoliberal cada vez mais 
dinâmica e fluida, assistimos ao levantar de diversas discussões acerca da negação de identidades, da aculturação, entre outras formas de subjugação ideológica das culturas dos povos. Sem dúvida, não podemos deixar de ver esse fenômeno em seu processo histórico como advindo das primeiras manifestações niilistas do século XIX.

As relações possíveis entre História e Ficção são frutos dos debates contemporâneos da própria historiografia. Nesta dinâmica, uma infinidade de possibilidades surge, dentro da compreensão da ficção enquanto fonte sensível para a ampliação dos saberes históricos. Para além disso, ambas, História e Ficção, comungam sua carga estrutural de narrativas, separadas, entretanto, pelos horizontes desiguais de expectativas: onde a História assegura-se pela autoridade sobre o passado e sua construção narrativa limitada às interpretações das fontes e dados; e a Ficção, liberta de tais amarras, faz uso da criatividade descompromissada com o real ou verossímil para cativar seu público leitor (PESAVENTO, 2003, pp. 8-9).

Como uma corrente unida em elos sintomáticos, a ficção literária é mantenedora de singularidades doutrinárias filosóficas de desprendimento. Seja nos conflitos geracionais de Pais e Filhos, de Ivan Turguêniev (1818-1883), nos debates solitários da consciência que não consegue mais suportar a si mesma do Memórias do subsolo, de Fiódor Dostoiévski (1821-1881), nos personagens infelizes da chamada geração perdida de um Ernest Hemingway (1899-1961) em O sol também se levanta (1926), na Molly Bloom que emana um "sim sim" em Ulisses (1922) entre fluxos mentais de um Jaime Joyce (1882-1941), ou, enfim, no pequeno e marginalizado Chinaski, de Charles Bukowski (1920-1994), em Misto Quente (1982), o que podemos perceber é que a literatura caminha, do século XIX ao início do século XX - ademais outras variantes, como o romance nacional -, sobre a estrada temática do niilismo, afirmando-o ou negando-o.

Pontualmente, o uso de uma obra selecionada permite a prática analítica da máxima evidenciada na pretensão textual. Nesse ínterim, levando em consideração que nenhum evento deve ter modificado tanto a cultura mundial como a Primeira Guerra Mundial antes da mesma, nosso objetivo aqui é analisar o conto do americano Howard Phillips Lovecraft (1890-1937) intitulado Dagon (1919), tomando-o como fonte histórica possível, a fim de analisar de que forma ele demonstraria um possível niilismo do pósPrimeira Guerra Mundial, marcado pela derrocada cultural das aristocracias da Europa Ocidental. Para tal, elegemos um debate conceitual marcado pelos seguintes verbetes: "representação" (CHARTIER, 2002) e "niilismo" (NIETZSCHE, 2005).

Corroborando com as feituras eficientes das análises de fontes diversificadas, condicionalmente na abordagem de aspectos menos explícitos da realidade, o método 
segue entre cruzamentos e uso de fontes singulares. O trato epistemológico com fontes pouco usuais vem sendo efetivado através de inúmeras experiências que dialogam com a crítica textual e os devidos aprofundamentos teóricos e metodológicos das interseções entre história, literatura, psicologia, antropologia e sociologia e seus respectivos produtos. Este trabalho constitui-se enquanto uma pesquisa documental posto que trata sua fonte enquanto documento passível de análise histórica.

Nossa fonte é o conto intitulado Dagon (LOVECRAFT, 2018, p. 49-54). Um conto curto, de narrativa ótica, com teor descritivo de cenário e sensações, de horror sobrenatural. Com logradouro temporal definido como do início da Primeira Guerra Mundial e logradouro espacial em algum lugar do Pacífico, a ficção busca a verossimilhança. A partir dele, pretendemos analisar as repercussões históricofilosóficas, sobretudo sob o advento do niilismo, no pós-Primeira Guerra Mundial, marcado pela derrocada cultural das aristocracias da Europa Ocidental (MEYER, 1987, p. 22).

Para tal, seletamos um debate conceitual marcado pelos seguintes verbetes: "representação" e "niilismo". Representação será tratado conceitualmente conforme as palavras de Chartier (2002, p. 23), quando o mesmo afirma que, dentro da ciência histórica:

Mais do que conceito de mentalidade, ela permite articular três modalidades de relação com o mundo social: em primeiro lugar, o trabalho de classificação e de delimitação que produz configurações intelectuais múltiplos, através das quais a realidade é contraditoriamente construída por diferentes grupos; seguidamente, as práticas que visam fazem reconhecer uma identidade social, exibir uma maneira própria de estar no mundo, significar simbolicamente um estatuto e posição; por fim, as formas institucionalizadas e objectivadas graças às quais uns <<representantes >> (instancias colectivas ou pessoas singulares) marcam de forma visível e perpetuada a existência do grupo, da classe ou da comunidade.

A problemática do <<mundo como representação >>, moldado através das séries de discursos que o apreendem e o estruturam, conduz obrigatoriamente a uma reflexão sobre o modo como uma figuração desse tipo poder ser apropriada pelos leitores dos textos (ou das imagens) que dão a ver e a pensar o real. Daí, neste livro e noutros, mais especificamente consagrados as práticas da leitura, o interesse manifestado pelo processo por intermédio do qual e historicamente produzido um sentido e diferenciadamente construída uma significação.

"Niilismo" será tratado, filosoficamente, de acordo com a seguinte problematização de Nietzsche (2005, p. 264) sobre o fazer filosófico:

Um filósofo recupera-se de outro modo e de outras coisas: recupera-se, por exemplo, no niilismo. A crença de que não existe nenhuma verdade, a crença dos niilistas é como um 
grande espreguiçamento para alguém que, como guerreiro do conhecimento, está continuamente em luta com meras verdades feias. Com efeito, a verdade é feia.

\section{Ecce Lovecraft: vida e obra de um homem trágico}

Comecemos com algumas palavras de Machado (2019, p. 70):

Para além de si mesma é que se encontra o domínio da palavra, e por mais universal que seja considerada a obra de determinado autor, tanto ele quanto seus escritos são sempre frutos de seu contexto histórico. Não se trata de determinismo, mas de entender que, para uma compreensão mais aprofundada do conteúdo estético e filosófico de uma produção literária, é necessário - devido à dialética autor-contexto , também atentar ao tempo e ao espaço em que as obras se presentificam.

Tendo isso em mente, prossigamos: Howard Phillips Lovecraft, comumente conhecido como H. P. Lovecraft, nasceu ao dia 20 de Agosto de 1890 em Providence, pequena cidade do estado de Rhode Island, nos Estados Unidos. Seu pai, Winfild Scott Lovecraft (1853-1898) era um vendedor de joias bem sucedido, ao passo que sua mãe provinha de uma família aristocrática notável cuja ascendência poderia ser remontada aos primeiros colonizadores americanos (BEZARIAS, 2006, p. 13).

O pai de Lovecraft, no entanto, morre quando o filho ainda era pequeno. A criação da pequena criança recai, então, inteiramente sobre sua mãe e seu avô, o industrial Whipple Van Buren Phillips. De saúde delicada, Lovecraft não frequentava a escola com regularidade. Apesar disso, o mesmo foi ensinado em casa com maestria, sobretudo no que diz respeito às línguas clássicas. Percebe-se que, desde pequeno, seu interesse pela leitura dos clássicos de ficção fantástica e de horror gótico foram incentivados, acima de tudo, por seu avô. Seu talento foi notado e aprimorado desde cedo. Aos poucos, Lovecraft foi se interessando por ciências, sobretudo Química e Astronomia; escrevia, então, jornais de teor científico a serem distribuídos entre seus próximos. Sua estreia enquanto escritor ocorreria, porém, em 1906 quando o mesmo enviou uma carta ao Providence Sunday Journal.

Contudo, com a morte do avô em 1904 e a consequente dilapidação do patrimônio familiar, a situação financeira de Lovecraft se torna difícil. Devido a crises nervosas, sua mãe morre em 1921. Então ele passa a ganhar dinheiro, majoritariamente, como ghost writter. Seu primeiro trabalho autoral publicado é o conto Dagon publicado em 1917 na revista Weird Tales. Lovecraft viria a se casar em 1926 com Sonia Greene, judia nascida na Ucrânia, mudando-se para Nova York, cidade da qual se desgostou, sobretudo pela presença maciça de imigrantes de raças variadas. $O$ racismo e a xenofobia continuaram a afetar a vida conjugal de Lovecraft ao ponto em que ele e Sonia decidiram se separar amigavelmente, e ele decidiu 
voltar a Providence, onde teve um período prolífico de produção até sua morte em 15 de março de 1937 (HOULLEBECQ, 2008, p. 28).

\section{Primeira Guerra Mundial: o cenário do monstruoso}

Em sua vida madura, Lovecraft acompanhou os jogos de guerra na Europa e suas interferências em outros mundos continentais: a Primeira Guerra Mundial ou Primeira Grande Guerra. O tempo narrativo contempla a passagem cronológica do conflito bélico, descrevendo seu começo e seu desfecho, ao menos no que diz respeito à presença e derrota da esquadra naval alemã na região do oceano asiático. O Impulso de Morte (FREUD, 1996), teorização freudiana em evidência, sintoniza-se com a visão geral construída sobre o período de guerra.

Conceito complexo, o Impulso de Morte trata de uma reflexão singular sobre os impulsos humanos. Elaborado enquanto especulação (GUTIERREZ-TERRAZAS, 2002, p. 91), esse impulso, algo para além do instinto e até mesmo opositor a este, permeia a análise aqui proposta. Porventura, seria demasiadamente raso fazer a análise deste conceito nesta argumentação, sendo seguramente conveniente a proposição sugerida de resvalamento para com a relação entre o cenário bélico real e seu fruto narrativo ficcional, fundamentalmente no que diz respeito às metáforas.

O conto Dagon traz em seu segundo parágrafo as descrições do evento histórico dentro da própria narrativa. A guerra naval no Teatro de Operações da Ásia e Pacífico é o ponto de partida para o inóspito tratado no conto, a transição intencional entre o mundo verossímil, natural, e o acesso a um mundo sobrenatural margeado de assombros relacionados ao oceano e seus mistérios. O conflito geral foi tratado por John Keegan (2006, p. 21) como "uma aberração cultural monstruosa", seu desfecho fomentou um imaginário social de "repulsa ao que a maioria das pessoas que a viveram encarava cada vez mais como uma matança sem sentido", como expressa o historiador Eric Hobsbawn (1995, p. 59).

O ocultismo surge contundente, através de elementos comuns ao período, com fascínios relacionados ao desconhecido de vestígios passados para além da memória histórica europeia. Mas Dagon (ou Dagom) é entidade presente no Velho Testamento do livro judaico-cristão, nos livros Josué e Juízes, além de partícipe das narrativas de autoria reputada ao profeta Samuel, como deus excelso dos filisteus. Desta mesma maneira aparece no conto, uma alegoria interpretativa da realidade assombrosa através de um passado arcaico.

Sua textura descritiva visceral-orgânica, a presença de uma antiguidade pelo prisma da arqueologia do assombro, com escritas perdidas, monolitos e leviatãs, dentre outros detalhes comuns às narrativas lovecraftianas, denotam sua natureza escatológica, elemento pertinente ao imaginário chocante do vívido no conflito bélico, numa espécie de exercício do pessimismo em latência nas décadas anteriores. A Primeira Guerra Mundial foi o cenário real que alimentou o 
realismo ficcional das nauseabundas sensações pessimistas que alimentam a narrativa lovecraftiana.

Os efeitos da guerra e seus tempos de transições marcaram não apenas o imaginário social europeu, mas, também, seu cotidiano. Não havia mais uma relação romântica com os conflitos, "a frustração existencial muito mais profunda começou a aparecer" (GUMBRECHT, 2010 , p. 311), tanto no primeiro quanto no segundo pós-guerra.

\section{Dagon: Lovecraf e o niilismo do pós-Guerra}

Conforme as palavras de Machado (2019, p. 74):

Mais antigo que o romance, o conto está intimamente ligado à cultura oral, como o atestam os trabalhos de coletânea elaborados sobre os mesmos, sobretudo a partir de esforços franceses e alemães. A partir do século XVI é que os contos começaram a ser colocados em forma escrita. O conto, enquanto gênero literário escrito, nasce atrelado ao apego em relação à cultura do medievo e é divulgado através da disseminação da imprensa. Sua teorização, porém, só se efetivará, de forma mais concreta com Edgar Allan Poe, no século XIX [...].

Mais especificamente em relação aos contos de Lovecraft, o que podemos perceber é um primário uso da forma e dos temas de Poe em seus primeiros contos como A fera na caverna, O Alquimista e A Tumba; posteriormente, o escritor, juntamente com a influência dele recebida por Lord Dunsay, compõe sua própria fórmula para composição de contos. Infelizmente não tendo alcançado grande sucesso em vida, a não ser por parte de alguns escritores que o cultuavam e chegavam mesmo a utilizar seus deuses e objetos fantásticos em suas próprias histórias - como é o caso de Robert Bloch (1917-1994), autor de Psicose , após sua morte seu nome se tornou famoso entre os leitores e críticos americanos através da criação da Editora Arkham, dedicada a coletar seus contos e publicar suas primeiras coletâneas. Assim, na década de 80 figuras como Deleuze (1925-1995) e Guatari (1930-1992) escreviam sobre ele, ao passo que nos anos 90 Michel Houellebecq (1956) repetia o feito de seus antecessores. Recentemente, desfazendo as críticas vulgares de pesquisadores que desqualificam a fantasia e o horror enquanto fontes históricas, Bezarias (2006, p 11) escreve que:

Na miríade de cenários, mundos e até universos que caracteriza o fantástico, a obra de H. P. Lovecraft ocupa lugar de destaque, por sua importância histórica, grande imaginação, influência sempre crescente sobre todo o gênero e representação precisa e tensa, ainda que bastante torcida e exótica do momento histórico em que foi gerada.

É a partir dessa noção acima retratada que pretendemos interpretar o conto lovecraftiano. Antes disso, porém, ainda é necessário trazer algumas coisas à tona. É preciso 
ter em mente que Lovecraft traz à ficção duas ideias que a filosofia já havia produzido no século XIX com Arthur Schopenhauer (1788-1860) e Friedrich Nietzsche (1844-1900): 1) a ideia de que a racionalidade é apenas uma parte de nosso ser, sendo nós, na maior parte de nossas ações irracionais, como bem mostrado no conto Além das muralhas do sono e 2) a ideia de que a existência humana é essencialmente trágica, ou seja, a raça humana não é capaz de comandar seu próprio destino, pois há forças superiores há ela, forças essas que desejam seu apocalipse, como no clássico conto $\mathrm{O}$ chamado de Cthulhu.

São ideias que permeiam o trato filosófico antecessor ao trabalho de Lovecraft, e surgem como pautas congruentes. Junto a essas ideias, percebe-se em sua existência cotidiana um racismo que o inspirou, sobretudo após sua estadia em Nova York, a criar algumas das subespécies de suas histórias, como aquelas em O Horror em Red Hook e em A Sombra sobre Insmouth (HOULLEBECQ, ANO, p. 31-2).

Vale notar que tanto o racismo quanto suas predileções políticas e mesmo, em última instância, a dimensão apocalíptica de suas criaturas, conforme veremos adiante no próprio Dagon - caso queiramos aqui o contextualizar em seu tempo e espaço - parecem apontar para um contexto histórico marcado pelo último momento efetivo de poder dos grupos aristocráticos vindos da Inglaterra nos Estados Unidos. Se o movimento romântico parece refletir um inicial aburguesamento da sociedade e o Realismo, conforme apontam Machado e Figueiredo (2019, no prelo) já reflete uma sociedade dominada ideologicamente pela burguesia, como no célebre romance francês Madame Bovary, de Gustave Flaubert (18211880), e uma crise já instalada na antiga aristocracia, na época de Lovecraft, o início do século $\mathrm{XX}$, seus contos parecem refletir a decadência quase total dos ideais morais, culturais e políticos da aristocracia americana.

Dito isso, foquemos mais especificamente em Dagon, o primeiro de seus contos a ser publicado depois de longos anos escrevendo poesias. Escrito em 1917 e publicado em 1919, Dagon conta, em primeira pessoa, o relato de um ex-combatente da Primeira Guerra que, após ter seu navio capturado pelos alemães, se torna prisioneiro de guerra, consegue escapar sozinho e então fica à deriva no oceano. Depois de sonhos atormentados, ele acorda e percebe já não estar em mar aberto, mas, sim, numa espécie de planície lamacenta, onde seu barco encalhara, que ele julga ter sido obra de alguma ativação vulcânica submarina. $O$ narrador espera que a lama seque e parte numa expedição a fim de conhecer o lugar. Andando, ele descobre um objeto que lhe causa estranheza: um alto monólito decorado com entalhes preciosos de figuras humanoides que se assemelhavam a peixes quase do tamanho de baleias. Em sua mente, ele imagina ser aquilo o totem representativo do deus fictício de qualquer tribo já há muito extinta, não a representação de uma criatura real. É quando a figura surge das águas, abraçando o monólito, o próprio Dagon. Nosso narrador foge, espantado. 0 
mesmo acorda num quarto do hospital militar, incerto do que ocorrera. Nos atentemos ao que nos interessa, suas últimas palavras delirantes:

É à noite, especialmente quando a lua está no quarto minguante, que vejo a coisa. Experimentei morfina, mas a droga fornece apenas um alívio transitório e me arrasta à dependência como um escravo sem esperança. Portanto, agora, tendo escrito um relato completo para informação ou divertimento desdenhoso dos meus semelhantes, estou para colocar um ponto final em tudo isso. Sempre me pergunto se tudo não poderia ter sido uma pura ilusão - uma mera fantasia febril enquanto eu, exposto ao sol ardente, delirava no bote aberto depois de minha fuga do navio de guerra. Pergunto isso, mas sempre vem diante de mim como resposta uma visão horrendamente vívida. Não posso pensar na profundidade do oceano sem estremecer diante das coisas desconhecidas, inomináveis, que devem estar rastejando e patinhando em seu leito viscoso, adorando seus ídolos de pedra antigo e lavrando suas imagens detestáveis em obeliscos subaquáticos de granito molhado. Sonho com o dia em que eles deverão erguer-se das enormes ondas e arrastar com suas garras fétidas os vestígios da humanidade débil, exaurida pela guerra - um dia em que a terra deverá submergir, e a escuridão do fundo do oceano emergirá em meio a uma balbúrdia universal. (LOVECRAFT, 2018, p. 54, grifos nossos)

A Primeira Guerra foi um grande evento na vida de todos aqueles que a experimentaram. Até mesmo quem não chegou a vivê-la, como é o caso do já à época debilitado Friedrich Nietzsche (1844-1900), escreveu sobre os altíssimos custos financeiros e humanos da paz armada à Europa pré-Primeira Guerra:

Se pudéssemos prescindir das guerras, tanto melhor. Eu saberia fazer um uso mais útil dos doze milhões que custa anualmente a paz armada à Europa; há ainda outros meios de homenagear a fisiologia do que com hospitais... Em poucas palavras, meios até muito bons: depois que o velho Deus for abolido, estarei pronto para reger o mundo... (NIETZSCHE, 2005, p. 303).

A violência na Primeira Guerra e na Segunda Guerra, então, extrapolava as limitações românticas dos conflitos anteriores. A nacionalização do mundo criou blocos mais densos, a tecnologia apropriada pela guerra produziu uma "industrialização da morte", onde a sensação gerada foi de que "limiar que fora atravessado pela imaginação de autoextinção nacional e, até mesmo, a autoextinção da humanidade" (GUMBRECHT, 2010, p. 312), ainda que isto seja mais sensível no segundo conflito.

Tendo visto o breve comentário anterior sobre a Primeira Guerra, que foi parte do contexto histórico do autor e o evento mais importante durante o nascedouro de Dagon, elencamos três perguntas para começar nossa análise do conto: o que seriam os vestígios da humanidade? Em que áreas estamos exauridos? E que significaria essa ascensão da escuridão do fundo do oceano a assinalar a balburdia universal? 
No que diz respeito aos vestígios da humanidade, Lovecraft parece querer tratar de um tipo de homem ainda mais inferiorizado que o homem comum, já inferior a seus deuses cósmicos. Em verdade, a segunda pergunta parece responder a primeira quando o narrador adjetiva a humanidade como "exaurida pela guerra". Porém, ainda nos fica a segunda questão: de que forma fomos exauridos?

Fisicamente, é óbvio. Mas em que sentido fomos esgotados além disso? Durante sua obra, em contos como Nyarlathotep, Lovecraft parece se deleitar melhor sobre essa ideia da humanidade cansada. No referido conto, é narrada a história de um deus que, após séculos de sono, é desperto e começa a se mover pelo mundo em forma humana fazendo truques para seduzir a humanidade. E aí fica evidente o caráter exaurido da humanidade ao qual Lovecraft se refere em Dagon: parece se tratar, para além de um esgotamento físico, de um esgotamento psicológico que se traduz num esgotamento cultural que põe fim às tradições de base aristocrática e abre caminho ininterrupto ao avanço da burguesia e do capitalismo. Nessa sociedade, filha da guerra, parece não haver espaço para a felicidade ou mesmo para uma simples vida digna que possa ser vivida com conformidade e respeito. É aqui que a velha máxima de Marx (1818-1883) parece finalmente ter se concretizado nos termos da cultura: "tudo que é sólido se desmancha no ar". Duas produções parecem demonstrar isso: o romance Mrs. Dalloway (1925), de Virginia Woolf (1882-1941) e a série televisa Downton Abbey (entre 2010 e 2015), ambas dispostas a retratar o cenário do início do século XX e as contradições sociais do momento, focando o primeiro na burguesia e o segundo na aristocracia.

Dessa forma, avançando à terceira questão, percebemos que dessa sociedade perdida não parece nascer outra sociedade que não também uma perdida: só que aqui há uma inversão: enquanto que nos primeiros anos pós-Primeira Guerra há negativismo ainda não parece haver niilismo. São nas gerações seguintes que parece haver o abraçar dessa tendência negativista enquanto tendência, sobretudo na passagem de um Hemingway a um Buckowski. Contudo, ademais essas reflexões que aqui não cabem se alongar, o que vemos em Lovecraft é que ele já abraça o niilismo desde o momento em que a guerra acaba, como se já sentisse a decadência cultural por vir. Nesse sentido, suas criaturas, em especial o Dagon de nosso conto, aparecem como seres responsáveis por dar-lhe vazão a seus sentimentos em relação ao contexto histórico que o cercava, no sentido de que a balbúrdia universal corresponderia a uma destruição reacionário do avanço burguês de volta ao domínio aristocrático. Além do tempo e do espaço, apenas eles poderiam combater a conjuntura que se lhes apresentava: nesse sentido, BEZARIAS (2006, p. 114-5) concorda conosco.

No fim, percebe-se que Lovecraft foi um escritor genial que respondeu a partir de suas possibilidades à conjuntura complexa da Primeira Guerra Mundial. Assim, conseguindo apontar desde seu primeiro conto o niilismo que cercaria nosso século XX e se estenderia até 
nosso século XXI. Para ele, de forma pessoal, o niilismo parece ser o resultado da combinação do esforço desnecessário de uma guerra capitalista com a dissolução progressiva de uma aristocracia que sempre fora responsável pela manutenção das tradições e da cultura.

\section{Considerações Finais}

A relação entre história e ficção é de fundamental importância para qualificar as sensações e sentimentos do passado. Uma maneira mais eficiente de entender as maneiras que as pessoas destes passados construíram suas realidades e as singularidades existenciais diante desta passagem de tempo, levemente margeada de passado e sonhada de futuro. A ficção é o exercício catártico da história vivida.

A realidade histórica da Primeira Guerra Mundial serviu como ponto de partida para o sentimento de assombro e pessimismo no conto Dagon. Através da relação entre a Primeira Guerra Mundial e a biografia pessoal de Lovecraft, pudemos estabelecer conexões que possibilitaram uma interpretação histórica do conto, focando na relação entre a decadência da aristocracia e o crescimento do niilismo conforme a Grande Guerra avançava.

Podemos, deste modo, entender como foram compostas as características que emergem do conto. O chamado constante ao fim do mundo e à irremediável pequenez do ser humano são, neste sentido, avisos de a transição dos valores aristocráticos aos valores burgueses, consagrados com a deflagração da Primeira Guerra, teriam reduzido todos os homens a coisas insignificantes, desprovidas de propósitos, a entes cheios de tédios, tédio esse que apenas seria possível de ser aliviado com a destruição total da Terra pelos Antigos: Dagon, Nyarlathotep Cthulhu e outros. Deuses esses que aparentam ser não apenas a face opostas do tédio humana: o sofrimento, mas a única saída possível dele. Esta pesquisa pretende se expandir buscando, em outros contos do mesmo autor, aspectos da história americana.

É um afastamento explícito da tendência universais e a intensificação da interpretação escatológica da realidade. Dagon nos remete isso, tal romanização cristianizada de desfecho da existência, que o pessimismo do século XIX propagou no lírico, no poético, na ficção de um modo geral. A pequenez humana, como expressão de uma subjetividade hegeliana, agora havia enamorado o cientificismo, mas sem perder sua carga pós-moderna de negação à razão transcendental. 


\section{REFERÊNCIAS}

BAQUERO, BEZARIAS, Caio Alexandre. Funções do mito na obra de Howard Phillips Lovecraft. USP: São Paulo, 2006. Disponível em: <https://teses.usp.br/teses/disponiveis/8/8147/tde-08012008-101659/publico/TESE_CAIO_ALEXANDRE_BEZARIAS.pdf>. Acesso em: 28 out. 2019.

CHARTIER, Roger. A História Cultural: entre práticas e representações. Lisboa: Difusão Editorial, 2002.

FREUD, Sigmund. Além do Princípio do Prazer: Psicologia de Grupo e outros trabalhos. Ed. Stand. Bras. das obras completas de Sigmund Freud, vol. XVIII. Rio de Janeiro: Imago, 1996.

GUMBRECHT, Hans Ulrich. Uma Rápida Emergência do “Clima de Latência”. In: TopoiRevista de História. Rio de Janeiro, volume 11, número 21, p. 303-317, julho-dezembro, 2010. GUTIERREZ-TERRAZAS, José. O conceito de pulsão de morte na obra de Freud. Ágora, Rio de Janeiro, 2002, vol.5, n.1, pp.91-100.

HOUELLEBECQ, Michael. H. P. Lovecraft: Against World, Against Life. Gollancz: Londres, 2008.

KEEGAN, John. Uma História de Guerra. Editora Companhia das Letras, São Paulo, 2006. LOVECRAFT, Howard Phillips. Dagon. In: Grandes Contos.São Paulo: Martin Claret, 2018. p. 49-54.

MACHADO, Adélio Alcino Sampaio Castro. Clarice Lispector e a Epistemologia: uma análise de O Ovo e a Galinha a partir da Crítica da Razão Pura, de Kant. In: GRAZIOLI, Fabiano Tadeu. (org.). A Expressividade e Subjetividade da Literatura. Atena Editora: Ponta Grossa, 2019.

MEYER, Arno. A força da tradição: a persistência do Antigo Regime (1848-1914). São Paulo: Companhia das Letras, 1987.

NIETZSCHE, Friedrich. Sabedoria para depois de amanhã. Martins Fontes: São Paulo, 2005.

PESAVENTO, Sandra Jatahy. O Mundo como Texto: Leitura da História e da Literatura. In: Revista de História da Educação, volume 7, número 14, Julho-dezembro, 2003. Disponível em: https://seer.ufrgs.br/asphe/article/view/30220. Acessado em: 10 de outubro de 2019.

SONDHAUS, Lawrence. A Primeira Guerra Mundial: História Completa. Editora Contexto, São Paulo, 2013. 